\title{
Fahr syndrome: A rare neurodegenerative disorder mimicking seizures
}

\author{
Luis Rafael Moscote-Salazar ${ }^{1}$, Camilo Palencia ${ }^{2}$, Tariq Janjua ${ }^{3}$, Loraine Quintana ${ }^{1}$, \\ Alexis Narvaez-Rojas ${ }^{4}$, Iván Lozada-Martinez' \\ ${ }^{1}$ Center of Biomedical Research, Universidad de Cartagena, Cartagena de Indias, Colombia \\ 2 Universidad de Santander, UDES, Cucuta, Colombia \\ ${ }^{3}$ Critical Care Medicine, Regions Hospital, Saint Paul, Minnesota, USA \\ ${ }^{4}$ Universidad Nacional Atónoma de Nicaragua, Managua, Nicaragua
}

Fahr's disease is a neurodegenerative disorder that is characterized by the presence of bilateral calcifications in the basal ganglia without an illustrative reason $(1,4,5)$. This characteristic differentiates it from the Fahr syndrome, the latter only refers to the existence of calcifications without taking into account the etiology. This means that Fahr syndrome involves a wide range of possible causes that justify the appearance of lesions (6).

65-year-old female patient who came to the emergency room due to contractions of facial muscles which were sudden onset accompanied by disorientation. There was an antecedent of arterial hypertension. Clinical examination and physical were normal, without any alterations in motility and sensitivity. Initial evaluation was conducted by internal medicine and neurology. A brain CT scan was performed showing bilateral gangliobasal, cerebral white matter, and cerebellar hemispheres' calcifications (Fig. 1). Her electroencephalogram was normal, chest x-ray without abnormalities and renal functions exams were without alterations. She was diagnosed with Farh's disease, and it was decided to continue outpatient neurology follow-up.

Fahr's disease occurs in individuals between the third and fifth decade of life. The most frequent site of calcifications corresponds to a pale globe, dentate nucleus, and striatum $(4,7,8)$. At present there is still confusion about the terminology used to encompass idiopathic cerebral calcifications, there being more than 35 ways of naming the presence of these (1). This is because in the first instance the

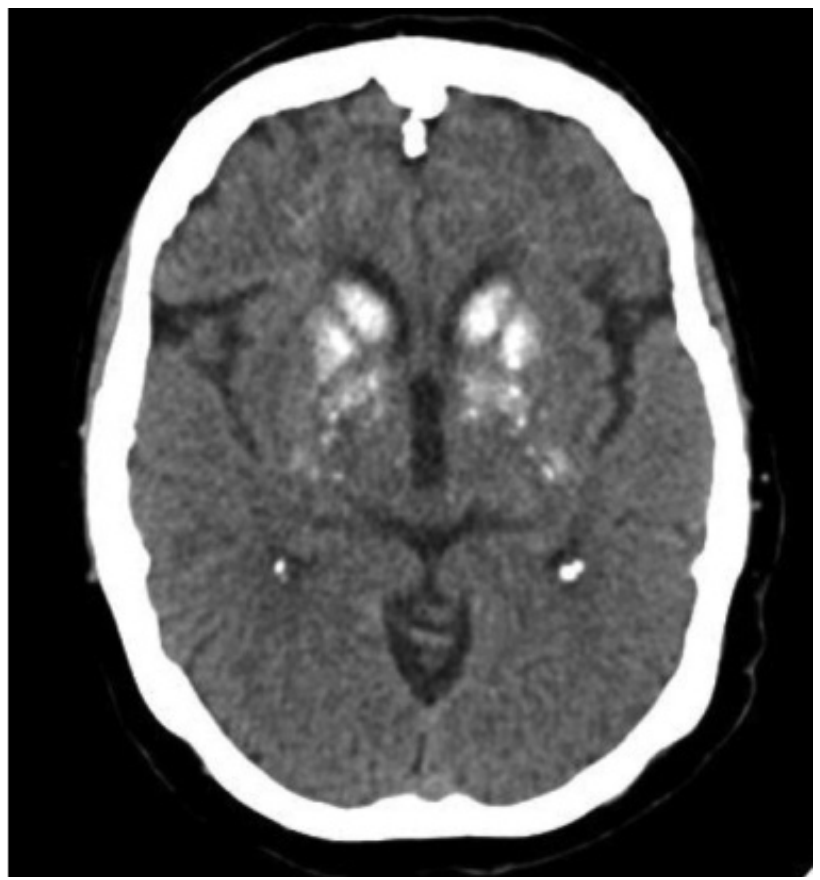

FIGURE 1. Computarized tomography of the patient, showing bilateral gangliobasal calcifications in the cerebral white matter and cerebellar hemispheres

term "Fahr's disease” was used as a synonym of calcifications located in basal ganglia and without an apparent pathophysiological explanation (9). This was based on the publication from the 1930s by Theodor Fahr, who reported a patient with calcifications in the CNS, neuropsychiatric disorders, and no medical history to explain the presence of calcifications $(6,10)$. 
In this way, different names have been established ranging from disease, Fahr syndrome, bilateral calcification in striated, pale, and dentate nuclei, to the current proposal of coining the name of familial cerebral calcification of primary origin $(1,2)$. It is a rare neurodegenerative pathology, characterized by the deposit of minerals and other elements in the perivascular and extracellular space of the basal ganglia, dentate nucleus, thalamus, and white matter $(2,11)$.

The prevalence ranges from values lower than 1 case up to 6 per 100 thousand inhabitants $(6,8,12)$. The pathophysiology of the disease is not completely elucidated. So far, mechanisms such as focal disruption of the blood-brain barrier, changes in the extracellular matrix, or alterations in the metabolism of glia calcium have been proposed $(2,13)$. It is believed that this causes changes in the lumen of the vessels, due to the chronic deposition of minerals, compromising the blood flow at the level of the basal ganglia (12). In addition, advances in molecular genetics suggest an important role for mutations in the PDGFB, PDGFRB, SCL20A2, and XPR1 genes in the pathophysiology of Fahr's disease $(2,4)$.

Of these genes, SCL20A2 has been the most investigated $(1,4)$. This gene codes for the type 2 sodium-dependent phosphate transporter 2 (PiT-2), a regulator of phosphate concentrations in the central nervous system. Regarding this, the study by Lagrue et al carried out in an animal model, found that PiT-2 is present in the basal ganglia (14). However, the lack of regulation in the expression of this protein in the brain may explain the greater probability of alterations at this anatomical level, when mutations arise in the mentioned gene (4).

The clinical manifestations mainly include movement disorders, with a predominance of parkinsonism in more than $50 \%$ of cases. Cognitive involvement is also observed, symptoms compatible with cerebellar involvement, speech alteration, and psychotic disorders $(2,4,11)$. It should be noted that some patients may debut with different pictures than those commonly described in the literature. Yang et al, in 2016, described the case of a patient under 40 years of age who had an ischemic stroke that involved the internal capsule (7). On the other hand, Calabrò et al (2014), reported the case of an older adult with a dementia disorder without movement disorders. However, there are asymptomatic patients, whose diagnosis is made by incidental imaging findings (11).

The Manyam diagnostic criteria are based on the presence of movement disorders and/or neuropsychiatric manifestations accompanied by bilateral calcifications in the basal ganglia, which may involve other anatomical areas. All of the above must be guided by a clinical history in which a family history of this disease is investigated, pathological antecedents such as hyperparathyroidism, mitochondrial encephalopathies, immunodeficiencies or infectious diseases, a good physical examination, and biochemical and endocrine parameters, which make it possible to rule out the presence of an underlying cause $(2,15,16)$. This is fundamental in the differentiation between Fahr's syndrome and Fahr's disease.

The tomography can detect between $1-20 \%$ of calcifications attributed to the physiological stages of the human being $(1,2)$. There is a greater likelihood of finding these lesions as the patient's age increases (2). This makes it difficult to establish the limit between calcifications due to old age and those caused by diseases, genetic mutations, or an unknown cause $(2,3)$. In this spectrum, we can find cerebral calcifications with an idiopathic family component.

The non-contracted CT is the exam of choice for the detection of CNS calcifications $(3,16)$. The results should be correlated with the patient's age, clinical picture, and personal history. In MRI lesions have a high signal in the $\mathrm{T} 1$ sequence and it is important to detect findings in the white matter that suggest myelination problems that may explain the manifestations $(5,9)$.

On the other hand, there is not in all cases a directly proportional relationship between the calcifications and neurological alteration of the patient. Whenever such lesions are detected in a patient under the age of 40 , the investigation of this case is peremptory (2).

At present, there is still no therapeutic approach protocol. Considering a symptomatic treatment based on the clinical picture with which the patient debuts (6).

\section{REFERENCES}

1. Batla A, Tai XY, Schottlaender L, Erro R, Balint B, Bhatia KP. Deconstructing Fahr's disease/syndrome of brain calcification in the era of new genes. Park Relat Disord. 2017;37:1-10.

2. Pistacchi M, Gioulis M, Sanson F, Marsala SZ. Fahr's syndrome and clinical correlation: a case series and literature review. Folia Neuropathol. 2016;3:282-94.

3. Alam ST, Aswani Y, Anandpara KM, Hira P. CT findings in Fahr's disease. BMJ Case Rep. 2015 Mar 20;2015:bcr2014208812.

Conflict of interest: none declared Financial support: none declared
4. Deng H, Zheng W, Jankovic J. Genetics and molecular biology of brain calcification. Ageing Res Rev [Internet]. 2015;22:20-38.

5. Zimny A, Zińska L, Bladowska J, Neska-Matuszewska M, Sasiadek M. Intracranial lesions with high signal intensity on T1-weighted MR images - Review of pathologies. Polish J Radiol. 2013;78(4):36-46.

6. Oviedo Gamboa I, Zegarra Santiesteban W. Características tomográficas en un paciente con Síndrome de Fahr, a propósito de un caso. Gac Médica Boliv. 2012;35(2):87-9. 
7. Yang CS, Lo CP, Wu MC. Ischemic stroke in a young patient with Fahr's disease: a case report. BMC Neurol. 2016;16(1):33.

8. Abubakar S, Saidu S. Idiopathic bilateral strio-pallido-dentate calcinosis (Fahr's disease): A case report and review of the literature. Ann Afr Med. 2012;11(4):234.

9. Garcia JL, Marcillo GM. Revisión de un paciente con calcificaciones en los núcleos basales. IntramedJournal. 2015;4(2):1-6.

10. Billard C, Dulac O, Bouloche J, Echenne B, Lebon P, Motte J, et al. Encephalopathy with calcifications of the basal ganglia in children. $A$ reappraisal of Fahr's syndrome with respect to 14 new cases. Neuropediatrics. 1989;20:12-9.

11. Calabro RS, Spadaro L, Marra A, Bramanti P. Fahr's disease presenting with dementia at onset: A case report and literature review. Behav Neurol. 2014;2014.
12. Saleem S, Aslam H, Anwar M, Anwar S, Saleem M, Saleem A, et al. Fahr's syndrome: literature review of current evidence. Orphanet J Rare Dis. 2013;8(1):156.

13. Eroglu U, Kahilogullari G, Demirel A, Anil A, Agahan U. Fahr syndrome seen with aneurysms: a case report. Turk Neurosurg. 2013;26(4):10-2.

14. Lagrue E, Abe H, Lavanya M, Touhami J, Bodard S, Chalon S, et al. Regional characterization of energy metabolism in the brain of normal and MPTP-intoxicated mice using new markers of glucose and phosphate transport. J Biomed Sci. 2010;17(1):91.

15. Manyam BV. What is and what is not "Fahr"s disease'. Park Relat Disord. 2005;11(2):73-80.

16. Sucre F, Casares K, Sandoval J. Bilateral calcinosis in striated, pale, and discussion of a case. Rev Mex Radiol. 2015;285-91. 